\title{
THE GHRELIN RECEPTOR ANTAGONIST [D-LYS3]-GHRP-6 REDUCES THE RISK BEHAVIOR IN THE RAT GAMBLING MODEL BY ALTERING THE TURNOVER OF DOPAMINE AND SEROTONIN
}

\author{
A. Lebedev, I. Karpova, I. Thyssen, N. Yakushina, K. Gramota, \\ E. Bychkov, P. Shabanov \\ FSBI «Institute of Experimental Medicine», St. Petersburg, \\ 197376, Acad. Pavlov str.12, Russia.
}

DOI: 10.19163/MedChemRussia2021-2021-259

E-mail: aalebedev-iem@rambler.ru

Introduction. Gambling as an object for study is of particular interest. In the international classifiers (ICD 10 and DSM-5) it stands out as a separate disease, is one of the non-chemical forms of addiction and has all the characteristics in the traditional understanding of this term: the development of tolerance (addiction), the development of addiction itself and the corresponding withdrawal syndrome. The most objective way to assess the degree of manifestation of a subject's gambling in laboratory conditions is the IOWA gambling task method, In recent years, the IOWA gambling task has been used in animal experiments. In our laboratory, a version of the model of this test in a three-arm maze in rats was developed.

Methods. For three weeks, the rats were trained in a three-arm maze using the food reinforcement (sunflower seeds). During the first five days, at the end of the 1st arm, the animals received 1 seed, at the end of the 2 nd arm, 2 seeds, and at the end of the 3rd arm, 3 seeds. In the following days, the reinforcement was differentiated: each entry in arm 1 was reinforced with 1 seed, each second entry in arm 2 was reinforced with 2 seeds and every third entry in arm 3 was reinforced with 3 seeds. 3 days after testing the rats were administered with $0.9 \% \mathrm{NaCl}$ or D-Lys3-GHRP-6. After 80 minutes, the brain structures were isolated. HPLC was used to determine the content of dopamine, serotonin in the hypothalamus, hippocampus, striatum, and olfactory tubercle.

Results. Intranasal administration of the ghrelin receptor antagonist [D-Lys3]-GHRP-6 $(20 \mu \mathrm{l}, 1 \mathrm{mg} / \mathrm{ml})$ increased the number of entries into the $1 \mathrm{st}$ arm (with a high (100\%) probability, but less reinforcement). The serotonin content significantly increased in the left hippocampus. The turnover of monoamines in the olfactory tubercle and striatum changed only in the right hemisphere, while the ratio of the content of 5-hydroxyindoleacetic acid to the content of serotonin increased in both structures. In the right striatum, these changes were also accompanied by an increase in the content of serotonin and dopamine metabolites.

Discussion. Thus, the ability of [D-Lys3] -GHRP-6 to change the strategy of choice in favor of the greatest probability, but the least amount of reinforcement, is based on an increase in the activity of the dopaminergic and serotoninergic systems in the dorsal and ventral striatum of the right hemisphere of the brain and the serotonin content in the hippocampus of the left hemisphere. 